\title{
Persistence of the nematicide fluensulfone in potato (Solanum tuberosum ssp. tuberosum) beds under field conditions
}

by Norshie, P.M., Grove, I.G. and Back, M.A.

Copyright, Publisher and Additional Information: This is the author accepted manuscript. The final published version (version of record) is available via Brill Online Please refer to any applicable terms of use of the publisher.

DOI: $10.1163 / 15685411-00003085$ 
1 Title: Persistence of the nematicide fluensulfone in potato (Solanum tuberosum ssp.

2 tuberosum) beds under field conditions

3

4

5

6 Patrick M Norshie ${ }^{1 *}$, Ivan G Grove ${ }^{2}$ \& Matthew A Back ${ }^{2}$

7

8

$9{ }^{1}$ Department of Agronomy, University College of Agriculture and Environmental Studies,

10 P. O. Box 27, Bunso, Eastern Region, Ghana.

11

12

13

$14{ }^{2}$ Nematology and Entomology Group, Crop and Environment Research Centre, Harper

15 Adams University, Newport, Shropshire, TF 10 8NB, UK

16

17

18

19 Correspondence: Patrick M Norshie (Ph.D.), Department of Agronomy, University

20 College of Agriculture and Environmental Studies, P. O. Box 27, Bunso, Eastern Region,

21 Ghana.E-mail: norshie@yahoo.com 
1 Summary - As part of a broader study to evaluate the efficacy of fluensulfone for control

2 of the potato cyst nematode Globodera pallida, two field experiments in Shropshire (at

3 Woodcote and Howle in 2010 and 2011, respectively) England, were used to monitor the

4 persistence of fluensulfone in potato beds treated with Nimitz $15 \mathrm{G} ®$ (fluensulfone) at 27

$5 \mathrm{Kg} \mathrm{ha}{ }^{-1}$. Fluensulfone dissipated at similar rates in the two fields, with a trend best

6 described by a sigmoidal curve. The time to $50 \%$ dissipation $\left(\mathrm{DT}_{50}\right)$ was 24.3 days at

7 Woodcote, and 23.7 days at Howle. No differences were found between the $\mathrm{DT}_{50}$ for

8 fluensulfone and that observed for fosthiazate. The short $\mathrm{DT}_{50}$ demonstrated for

9 fluensulfone in this study is an attribute in that it may pose a negligible hazard to the

10 environment. However, its persistence at an effective dose may be long enough to be

11 effective over the peak hatch period of G. pallida.

21 Keywords - Fosthiazate; Globodera pallida; half-life; management; Potato cyst 22 nematodes 
Nematicides are a vital component in the integrated management of potato cyst nematodes (PCN), Globodera rostochiensis (Wollenweber) Skarbilovich, (Woll.) and G. pallida (Stone) Behrens in the United Kingdom (Haddock \& Evans, 1998). However, due

4 to environmental concerns and the risk posed to human health a number of nematicides

5 have been withdrawn. The limited remaining options (fosthiazate and oxamyl) may not 6 qualify for reregistration under Regulation (EC) No 1107/2009, which is based on stringent 7 hazard based criteria. The organophosphate, fosthiazate (as Nemathorin 10G; Syngenta 8 Crop Protection Ltd, Cambridge, UK) and the carbamate, oxamyl (as Vydate 10G; DuPont 9 Crop Protection Ltd, Stevenage, UK) are acetylcholine esterase inhibitors (Opperman \& Chang, 1990), which are reported to control PCN by interfering with host finding abilities 11 of the infective juvenile (Evans et al., 1982), which ultimately reduces the extent of root 12 damage during infection. However, fosthiazate and oxamyl have been reported as being ineffective for the control of G. pallida (Whitehead et al., 1994). The challenge for nematicides to achieve effective control of G. pallida is commonly ascribed to their short term persistence in soil (Whitehead et al., 1984; Whitehead et al., 1991); Haydock et al., 2012). The rapid degradation of fosthiazate and oxamyl combined with the slower hatching longer period. A study of the hatching behaviour of G. pallida in relation to persistence of the nematicide oxamyl, for instance, showed that an effective control will require it to extend for greater than 3 weeks (Haydock \& Evans, 1998)

Fluensulfone is a relatively new nematicidal compound from ADAMA Agricultural Solutions Ltd., with activities against the root-knot nematode, Meloidogyne species (Oka et al., 2009; Oka et al., 2013; Morris et al., 2015; Oka et al., 2012), and the migratory nematodes, Pratylenchus penetrans, P. thornei and Xiphinema index (Oka, 2014).

26 Fluensulfone is suggested (Kern et al., In Press) to involve metabolic impairment, leading 
1 to an inability to utilize lipid stores and death. Previously, we have presented findings on

2 the efficacy of fluensulfone against G. pallida under field conditions in Shropshire,

3 England (Norshie et al.,2016), where it was shown that a full rate application of

4 fluensulfone (as Nimitz $15 \mathrm{G}$ at $27 \mathrm{~kg} \mathrm{ha}^{-1}$ ) at potato planting could be an option for the

5 control of G. pallida. During these field experiments, the loss of fluensulfone from the

6 potato beds was also determined. Since persistence influences nematicide efficacy, it was

7 critical to establish whether fluensulfone will persist in soil for a sufficient period to reduce

8 G. pallida effectively. The specific objectives were to determine the dissipation rate $(k)$

9 and the time to $50 \%$ dissipation $\left(\mathrm{DT}_{50}\right)$ for the full rate application of fluensulfone in

10 comparison to the field rate application of the nematicide fosthiazate (Nemathorin 10G).

12 Materials and methods

EXPERIMENTAL SITES, NEMATICIDE APPLICATION AND GENERAL 15 AGRONOMY

The experiments used commercial potato growers' fields at Woodcote (UK Ordnance 18 Survey Grid Reference: SJ 76901 15708) in 2010, and at Howle (UK Ordnance Survey 19 Grid Reference: SJ 69485 23830) in 2011. The soils at both sites were sandy clay loam $20(1.8 \%$ organic matter, $6.6 \mathrm{pH}, 14.8 \%$ moisture content at $5 \mathrm{KPa}$ at Woodcote; $2.2 \%$ organic 21 matter, $5.6 \mathrm{pH}, 13.9 \%$ moisture content at $5 \mathrm{KPa}$ at Howle). The growers cultivated the 22 fields according to standard commercial practice. Both fields had received fosthiazate 23 treatments five years prior to the experiments. Experimental plots measured $3.6 \mathrm{~m}$ wide 24 and $6.0 \mathrm{~m}$ long, and comprised of four ridges (drills) with the outer two acting as guards. 25 The experiments utilised certified potato (Solanum tuberosum ssp. tuberosum) seed (Super 
1 Elite grade II) graded to $35-45 \mathrm{~mm}$ of the variety Estima (PCN susceptible). Nimitz $15 \mathrm{G}$

2 (ADAMA Agricultural Solutions Ltd., Airport City, Israel) and Nemathorin 10G

3 (Syngenta Crop Protection Ltd., Cambridge, UK) were broadcasted on the beds at $27 \mathrm{~kg}$

$4 \mathrm{ha}^{-1}$ and at $30 \mathrm{~kg} \mathrm{ha}^{-1}$ respectively, and incorporated to $0-20 \mathrm{~cm}$ depth using a tractor

5 mounted Jones Bed-former (Jones Engineering Westwood Doncaster, UK). The Estima

6 seed tubers were planted manually at a depth of $10-15 \mathrm{~cm}$ and $25 \mathrm{~cm}$ in-row spacing in the

7 rows on 20 and 21 May 2010 at Woodcote, and 21 and 22 April 2011 at Howle. The

8 experiments were randomized complete block designs with five replications.

SOIL SAMPLING, DETERMINATION OF SOIL TEMPERATURE AND AMOUNT OF PRECIPITATION

12 Soil sampling for fluensulfone laboratory analysis started within 4 hours of planting (i.e.

13 zero days after application; 0 DAA), and then at 7-8 day intervals over the entire duration

14 of the experiments. At each sampling point, 10 soil cores $(2.5 \mathrm{~cm}$ diameter $\times 20 \mathrm{~cm}$ deep $)$

15 were taken from each plot, bulked, thoroughly mixed and transferred to a $500 \mathrm{~mL}$

16 polypropylene bags, which were sealed and stored, within 1 hour after sampling, at $-20^{\circ} \mathrm{C}$

17 for analysis. Soil temperature was recorded with a pair of Tinytag Plus 2 temperature data

18 loggers (Gemini data loggers, West Sussex, UK) buried at $15 \mathrm{~cm}$ depth. Rainfall records

19 were taken at Harper Adams University, Newport in Shropshire (approximately $6.0 \mathrm{~km}$ 20 from the experiments).

23 Technical-grade fluensulfone (> 95\% purity, lot number 130291-PF-2) was supplied by 24 ADAMA Agricultural Solutions Ltd, Airport City, Israel. Analytical standard grade 
1 fosthiazate (98.6\% purity) was purchased from Fluka Analytical UK Ltd. Acetonitrile

2 (99.99\% purity) and orthophosphoric acid (85\% purity) were purchased from Fisher

3 Scientific Ltd and BDH Laboratory supplies UK Ltd, respectively. Water for all analyses

4 was prepared by Purite Stillplus HP Pack. Fluensulfone and fosthiazate were quantified in

5 the soil samples by HPLC (High Performance Liquid Chromatography) analysis on an

6 Agilent Technologies 1100 series apparatus (Agilent Technologies Ltd, Stockport, UK),

7 which was equipped with an auto-sampler, a binary pump system, multiple wavelength UV

8 detectors, and operated by Agilent ChemStation B.03 software for windows. The

9 chromatographic conditions for analysing fluensulfone were set according to a protocol by

10 ADAMA Agricultural Solutions Ltd. The separation column was a reversible Hypersil

11 Gold column $(250 \times 4.6 \mathrm{~mm}$, and $5 \mu \mathrm{m}$ particle size $)$, and was used at $40^{\circ} \mathrm{C}$ oven

12 temperature. The mobile phase comprised acetonitrile (eluent A) and $0.1 \%$

13 orthophosphoric acid in water (eluent B) mixture, and was set to flow at the gradient

14 shown in Table 1 . The injected volume $(20 \mu \mathrm{L})$ was monitored at $254 \mathrm{~nm}$ peak area.

15 Fosthiazate was analysed using the same column., and a $20 \mu \mathrm{L}$ aliquot was injected and

16 but monitored at $230 \mathrm{~nm}$ peak area (Osborn et al., 2010). The mobile phase was an

17 acetonitrile and water mixture $(1 / 1 \mathrm{v} / \mathrm{v})$, and flowed at $1 \mathrm{~mL} \mathrm{~min}^{-1}$. Under the above

18 conditions, fluensulfone and fosthiazate eluted at ca. $18.1 \mathrm{~min}$ and $5.9 \mathrm{~min}$, respectively.

20 CALIBRATION OF HPLC EQUIPMENT

22 A stock solution each of fluensulfone and fosthiazate was prepared by dissolving $10 \mathrm{mg}$ 23 chemical in $100 \mathrm{~mL}$ solvent $(1 / 1 \mathrm{v} / \mathrm{v}$ mixture of acetonitrile and water) to give a dilution of $24100 \mu \mathrm{g} \mathrm{mL}^{-1}$. Dilutions of fluensulfone and fosthiazate $(0.001,0.01,0.1,0.25,0.50,1.00$, $252.5,5$ and $10 \mu \mathrm{g} \mathrm{mL}$ ) were prepared from the stock solutions. Each dilution was injected 
1 into the HPLC four times, starting with the lowest. The stock solutions were stored at $4^{\circ} \mathrm{C}$

2 until were needed for analysis where fresh working dilutions were prepared. The validities

3 of the methods were determined by correlations between peak areas and concentrations.

4 The correlations in each case were positively linear, and occurred over $0.1,0.25,0.50$ and

$51.0 \mu \mathrm{g} \mathrm{mL}$ for fluensulfone $(\mathrm{a}=11.18 \mathrm{~b}+0.21, r=0.996)$ and over $0.10,1.0,2.5$ and $5.0 \mu \mathrm{g}$

$6 \mathrm{~mL}$ for fosthiazate $(\mathrm{a}=14.56 \mathrm{~b}+0.25, r=0.999)$.

10 The recovery of fluensulfone from field soil was determined by spiking the soil with either technical grade fluensulfone or Nimitz 15G. The field soil was collected from the plots left untreated at Woodcote and Howle in 2010 and 2011, respectively. The soil was air dried and sieved to $<2 \mathrm{~mm}$. Triplicate $20 \mathrm{~g}$ sub-samples were weighed into $100 \mathrm{~mL}$ glass

14 shaking bottles, and was either spiked with $1 \mathrm{~mL}$ of $50 \mu \mathrm{g} \mathrm{mL} \mathrm{L}^{-1}$ of fluensulfone or mixed 15 with $27 \mathrm{mg}$ Nimitz 15G. The samples were allowed to stand for ca. 30 min before a $20 \mathrm{~mL}$ acetonitrile/water mixture (1/1, v/v) was added, and the mixture agitated at $300 \mathrm{rpm}$ for $1 \mathrm{~h}$

17 on a HS 501 Digital reciprocal shaker $\left(\mathrm{IKA}^{\circledR}\right.$-Werke GmbH \& Co. KG, Staufen, 18 Germany). The samples were then allowed to stand for ca. $1 \mathrm{~h}$ before $1 \mathrm{~mL}$ of the 19 supernatant was removed with a $2 \mathrm{~mL}$ syringe (BD Plastics Ltd, UK) and sieved through a $20 \quad 0.2 \mu \mathrm{m}$ pore size Polyvinylidene Difluoride (PVDF) syringe filter (GE Healthcare UK Ltd) 21 into a screw cap $2 \mathrm{~mL}$ HPLC glass vial. A similar protocol was used to determine the 22 recovery of fosthiazate from soil, but only analytical grade fosthiazate was used and the 23 samples were shaken for a period of $3 \mathrm{~h}$ (Osborn et al., 2010). The mean recovered 24 fluensulfone from the Nimitz $15 \mathrm{G}$ treated-soil was $85.8 \%(82.8-88.7 \%)$, which was lower 25 than $98.2 \%(92.4-103 \%)$ for the technical grade fluensulfone spiked-soil. For this reason, 
1 the Nimitz $15 \mathrm{G}$ treated-soil was agitated further, and analysed after 2, 3, 4 and $12 \mathrm{~h}$ of

2 agitation. Subsequent analysis showed that most fluensulfone (91\%) was extracted after $3 \mathrm{~h}$

3 of agitation. The recovered fosthiazate was $92 \%(86-102 \%)$.

\section{RELEASE OF FLUENSULFONE FROM THE GRANULAR FORMULATION}

6 As part of the validation of the method, two tests were conducted to determine the release

7 rates of fluensulfone from the granular formulation. The tests were made in order to

8 optimise the extraction of fluensulfone from the soil samples, and to determine any effects

9 of the formulation on the availability of fluensulfone upon application to the soil. Test 1 ,

10 which was repeated three times, quantified total fluensulfone in the formulation. With this,

$1127 \mathrm{mg}$ of granules (4.05 mg fluensulfone) were transferred in $100 \mathrm{~mL}$ glass bottles and

12 shaken at $300 \mathrm{rpm}$ for $1,2,3,4$ and $12 \mathrm{~h}$ in $20 \mathrm{~mL}$ of acetonitrile without soil. This was

13 repeated three times. At each time point, $1 \mathrm{~mL}$ of the solvent was sampled and analysed for

14 fluensulfone. Test 2 (repeated twice) was undertaken to determine a water-induced release

15 of fluensulfone from the formulation. In Test 2, $27 \mathrm{mg}$ of the granules were placed in each

16 of ten plastic tubes $(1.0 \mathrm{~cm}$ wide $\times 2.0 \mathrm{~cm}$ high $)$ sealed at the bottom with nylon mesh $(53-$

$17 \mu \mathrm{m}$ aperture). Half of the tubes were placed upright in the wells of a 24-well plate to which

$181 \mathrm{~mL}$ of distilled water was added, submerging the granules. The plate was covered, sealed

19 with parafilm and incubated at $5^{\circ} \mathrm{C}$ (to minimise potential degradation). The other half was

20 similarly treated and incubated at $20^{\circ} \mathrm{C}$. After $1 \mathrm{~h}$ of incubation, each tube was carefully

21 lifted, and the entire water was removed by a pipette and transferred to $100 \mathrm{~mL}$ conical

22 flasks. The well was rinsed trice, and the water added to the flask. Fresh distilled water was

23 added to the well and the plates incubated as before. The water in the flask was made up to

24 the $100 \mathrm{~mL}$ mark (1/100 dilutions), and a $1 \mathrm{~mL}$ subsample was filtered through $0.2 \mu \mathrm{m}$ 
1 sieves to analyse for fluensulfone. Sampling and analysis for fluensulfone was repeated at

$212 \mathrm{~h}$ and $24 \mathrm{~h}$, and then at $3.5,7,17,23,35$ and 41 days after incubation.

3 QUANTIFICATION OF FLUENSULFONE AND FOSTHIAZATE IN SOIL

4

5 Soil samples to be extracted were removed from $-20^{\circ} \mathrm{C}$ storage, and left in plastic trays

6 overnight to thaw. Each sample was then thoroughly mixed, and a $20 \mathrm{~g}$ sub-sample

7 transferred in a $100 \mathrm{~mL}$ glass shaking bottle and agitated in $20 \mathrm{~mL}$ of acetonitrile and water

$8(1 / 1 \mathrm{v} / \mathrm{v})$ at $300 \mathrm{rpm}$ for $3 \mathrm{~h}$. The bottle was left to stand for at least 30 minutes when $1 \mathrm{~mL}$

9 of the supernatant was sampled, and was either analysed immediately or stored at $-20^{\circ} \mathrm{C}$

10 for future analysis.

14 The measured concentrations for each replicate plot were regressed against time (DAA), and the parameters $k$ and $\mathrm{DT}_{50}$ estimated from curves which best fitted the data (Osborn et

16 al., 2010). Curve fitting and parameter estimations were carried out using SigmaPlot V.12

17 (Systat Software, Inc. London, UK). The parameters obtained were analysed by one-way 18 ANOVA using Genstat v.14 (VSN International Ltd., Hemel Hempstead, UK). There were 19 a few instances when the 0 DAA samples contained lower concentrations than were 20 detected at 7 DAA. In these instances, the starting concentration for calculating the $\mathrm{DT}_{50}$

21 value was estimated from the fitted curve as recommended by Forum for the Co-ordination 22 of pesticide fate models and their use, FOCUS. (FOCUS 2006). 
4 Figure 1 shows the soil temperature and precipitation during the field experiments. The 5 mean soil temperature was $17.04{ }^{\circ} \mathrm{C}$ at Woodcote and $14.96^{\circ} \mathrm{C}$ at Howle. No precipitation was recorded until 7 DAA. Total rainfall recorded over 126 days was $378.8 \mathrm{~mm}$ and 370.0

$7 \mathrm{~mm}$ at Woodcote and Howle, respectively.

11 Figure 2 shows the concentration of fluensulfone and fosthiazate in the $20 \mathrm{~cm}$ soil depth of 12 potato beds over 126 days at Woodcote and Howle in 2010 and 2011, respectively. The mean concentration of fluensulfone at 0 DAA at Woodcote was $2.35 \mathrm{mg} \mathrm{Kg}^{-1}$ soil, and was

14 slightly higher by $7 \mathrm{DAA}\left(2.69 \mathrm{mg} \mathrm{Kg}^{-1}\right.$ soil). It then dissipated quite rapidly through 14 DAA and 21 DAA to $0.54 \mathrm{mg} \mathrm{Kg}^{-1}$ soil (ca. $63 \%$ dissipation) by 28 DAA. Subsequent 16 losses occurred rather slowly, with the concentrations fluctuating between 0.27 and 0.12 $17 \mathrm{mg} \mathrm{Kg}^{-1}$ soil. The loss of fluensulfone from the potato beds at Howle followed a similar 18 trend to that observed at Woodcote. The mean concentration at 0 DAA was $1.90 \mathrm{mg} \mathrm{kg}^{-1}$ 19 and was slightly higher $\left(2.10 \mathrm{mg} \mathrm{Kg}^{-1}\right.$ soil) by 7 DAA before dropping rapidly through 14 , 2021 and 28 DAA to $0.27 \mathrm{mg} \mathrm{Kg}^{-1}$ soil (ca. $75 \%$ dissipation) by $35 \mathrm{DAA}$. Further losses 21 appeared rather slowly, with fluctuating concentrations detected up until the final sampling 22 at 126 DAA. Overall, fluensulfone dissipated at similar rates in the two fields (Table 2), 23 and the trends followed a sigmoidal equation (Figure 2). The $\mathrm{DT}_{50}$ varied from 19.6 to 30.0 24 days, with a mean of 24.3 days at Woodcote, and varied from 13.9 to 31.5 days, with a 
mean of 23.7 days at Howle. Fosthiazate dissipated at different rates in the two fields (Table 2). The trend was exponential at Woodcote (Figure 2), with $34 \%$ dissipation occurring within the first 7 DAA. This was then followed by a period of no significant loss until 42 DAA when $0.23 \mathrm{mg} \mathrm{Kg}^{-1}$ soil remained (ca. $87 \%$ dissipation). The trend was exponential sigmoidal at Howle (Figure 2), with no losses until after 7 DAA when the 0 DAA concentration $\left(1.80 \mathrm{mg} \mathrm{kg}^{-1}\right.$ soil $)$ dissipated significantly $(P<0.001)$ to $0.52 \mathrm{mg} \mathrm{Kg}^{-1}$ soil by 21 DAA (ca. $71 \%$ dissipation). The $\mathrm{DT}_{50}$ ranged from 10.4 to 35.2 days, with a mean of 21.3 days at Woodcote, and 16.3 - 21.1 days, with a mean of 18.8 days at Howle. The $\mathrm{DT}_{50}$ values obtained did not differ between the nematicides or the fields (Figure 3).

\section{RELEASE OF FLUENSULFONE FROM THE GRANULAR FORMULATION}

Fluensulfone extracted by acetonitrile and the release from the granular formulation into water as functions of time are shown in Figure 4. Assuming no degradation had occurred during the test, the extraction with acetonitrile showed that ca. $91 \%$ (3.67 $\mathrm{mg}$ ) of the expected fluensulfone ( $4.05 \mathrm{mg}$ ) was available for extraction by $12 \mathrm{~h}$ of shaking, and much of this $(3.66 \mathrm{mg})$ was extracted by the $4^{\text {th }}$ hour. Water, on the other hand, induced a gradual, but incomplete, release of fluensulfone from the formulation within 41 days of incubation. The amount and rate of release depended mainly on the temperature and duration of incubation. Except for the samples collected at 1 and $12 \mathrm{~h}$ (first two points shown on figure $4 \mathrm{~b}$ ), when as much fluensulfone was released thereafter at $5^{\circ} \mathrm{C}$ as at $20^{\circ} \mathrm{C}$ incubation temperature, the amount released thereafter at later sampling times was greater at $20^{\circ} \mathrm{C}$ than at $5^{\circ} \mathrm{C}$, figure $4 \mathrm{~b}$. The percentage cumulative release, as of 41 days of incubation, was significantly lower $(2.93 \mathrm{mg})$ for material incubated at $5^{\circ} \mathrm{C}$ than that seen 
1 at $20^{\circ} \mathrm{C}(3.53 \mathrm{mg})(P<0.001)$, and the amounts released at either incubation temperature

2 correlated positively $\left(r^{2}=0.99 ; P<0.001\right)$ with the duration of incubation.

4 Discussion

The $\mathrm{DT}_{50}$ for fluensulfone in this study suggests the half-life (persistence) is no

6 longer than 24 days, and was similar to that observed for fosthiazate. This implies that half

7 the concentration of both nematicides may have dissipated prior to peak $\mathrm{J} 2$ hatch at

8 between 42 - 56 days (Haydock and Evans, 1998) Conversely, whilst the $\mathrm{DT}_{50}$ may be an

9 important index for environmental persistence it may convey limited, if any, information

10 on the minimum effective dosage for control of G. pallida or the length of that control.

11 Indeed, control of G. pallida by the full rate fluensulfone treatments was evident in the

12 field experiments (Norshie et al., 2016), which provided the soil for these laboratory

13 analyses. This suggests that soil concentrations were at effective concentrations. Also,

14 preliminary in vitro experiments (unpublished data) showed that fluensulfone acted against

15 G. pallida hatching of $\mathbf{J} 2$ G. pallida from two-year-old cysts incubated in the technical-

16 grade at concentrations ranging from 0.00425 to $0.608 \mathrm{mg} \mathrm{L}^{-1}$ and it was deduced from the

17 cumulative hatch curve that there was complete inhibition of $\mathrm{J} 2$ emergence by the fifth

18 week of incubation in fluensulfone. Similarly, the motility of $\mathrm{J} 2$ G. pallida was reduced

19 following incubation in fluensulfone at $0.0078-32 \mathrm{mgL}^{-1}$ for $24-72 \mathrm{~h}$. The concentration

20 of fluensulfone remaining in the beds beyond 24 DAA ranged from 0.6 to $1.2 \mathrm{mg} \mathrm{Kg}^{-1}$ soil

21 at Woodcote, and from 0.4 to $0.9 \mathrm{mg} \mathrm{Kg}^{-1}$ soil at Howle. Even with the calculated DT 50

22 suggesting short persistence, fluensulfone may remain in the soil in sufficient

23 concentrations to control G. pallida, and the same can be said of fosthiazate, which had a

24 similar persistence to fluensulfone. 
1 The dissipation kinetics for fluensulfone were similar for both fields. This could be

2 explained by the similar soil and growing conditions under which the experiments were

3 done. The release kinetics of fluensulfone from the formulation into water suggest that the

4 active substance may be readily available for entry into water once the granules become

5 hydrated and that the carrier material is unlikely to be a limiting factor to its availability to

6 soil water. Even though the incubation tests are made under laboratory conditions not

7 directly comparable to field situations, gradual release of fluensulfone from the granular

8 formulation in the soil is plausible, and may influence the persistence of fluensulfone by

9 retarding its availability to degradation and/or leaching processes, which are concentration

10 dependent. The lag phase of seven days preceding the dissipation of fluensulfone in both

11 fields could be due to an initial delay in release which could limit availability in the soil

12 during this period. A general property of non-fumigant nematicides is that their availability

13 and subsequent redistribution in the soil are achieved by soil moisture as affected by

14 rainfall or irrigation application (Noling, 2003; Smelt \& Leistra 1992; Rich et al.,2003).

15 As shown in Figure 1, no precipitation occurred at either site until 7 DAA. Therefore, the

16 release kinetics from the formulation may partly explain the initial delay in dissipation

17 measured in the field plots. Indeed, the loss of fluensulfone from the plots in both fields

18 coincided with the onset of precipitation/rainfall, and the subsequent rapid decline in

19 concentration occurred during the period of highest precipitation. This highlights the likely

20 importance of soil moisture on the overall persistence of fluensulfone. If the laboratory,

21 results could be extrapolated to field situations, then both the amount and frequency of

22 irrigation/rainfall, following application of fluensulfone to potato beds, could affect the

23 persistence in the rhizosphere of the potato and, thus, its ability to protect roots from

24 invasion. Soil samples in this study were only collected from the depth of incorporation

25 (i.e. topmost $15-20 \mathrm{~cm}$ ) and, assuming that there was leaching during the sampling

26 period, it could be that fluensulfone was leached to deeper layers rather than being 
1 degraded as such. The same could be suggested for the loss of fosthiazate, which is already

2 known to be prone to leaching (Karpouzas et al., 2007). Further laboratory/controlled

3 environment studies modifying these factors could determine their likely influence on

4 persistence, and therefore, the efficacy of fluensulfone.

5 In summary, the short $\mathrm{DT}_{50}$ demonstrated for fluensulfone in this study is an attribute in

6 that it may pose a negligible hazard to the environment. However, its persistence at an

7 effective dose may be long enough to be effective over the peak hatch period of G. pallida.

\section{Acknowledgements}

11 We thank the staff at the Crop and Environment Research Centre at Harper Adams

12 University, and Mr Matthew Rodenhurst, in particular, for his efforts in securing field sites

13 and applying the nematicides during the field experiments. Also, we appreciate the

14 guidance and assistance by Mr Kevin Jones and Mr Amjad Ali during HPLC analyses of 15 the soils. A special mention goes to the late Dr Patrick P. J. Haydock, who initiated the 16 work reported in this paper. The first author was in receipt of a Ph.D. studentship from 17 ADAMA Agricultural Solutions Ltd, Airport City, Golan Street, Israel.

\section{References}

20 Evans, K. (1993). New approaches for potato cyst nematode management. Nematropica 23 , $21 \quad 221-231$.

22 Evans, S.G. and Wright, D.J., (1982). Effects of the nematicide oxamyl on life cycle stages of Globodera rostochiensis. Annals of applied Biology, ${ }_{100}$, pp. $5_{11}-5_{19}$. DOI: 
1 Focus (2006). Guidance Document on Estimating Persistence and Degradation Kinetics

2 from Environmental Fate Studies on Pesticides in EU Registration. Report of the

3 FOCUS (FOrum for the Co-ordination of pesticide fate models and their USe) Work

4 Group on Degradation Kinetics, EC Document Reference SANCO/10058/2005 version 2.0, June 2006. http://focus.jrc.ec.europa.eu/ (accessed 2 March 2012).

Haydock, P.P.J. \& Evans, K (1998). Management of potato cyst nematodes in the UK: an integrated approach? Outlook of Agriculture ${ }_{27}, 2_{53}-2_{60}$.

Haydock, P.P.J., Ambrose, E.L., Wilcox, A. \& Deliopoulos, T. (2012). Degradation of the nematicide oxamyl under field and laboratory conditions. Nematology ${ }_{14}, 3_{39}-3_{52}$. DOI: 10.1163/156854111X597485

Karpouzas, D.G., Pantelelis, I., Menkissoglu-Spiroudi, U., Golia, E. \& Tsiropoulos, N. G. (2007). Leaching of the organophosphorus nematicide fosthiazate. Chemosphere ${ }_{68}, 1_{359^{-}}$ 1364. DOI: https://doi.org/10.1016/j.chemosphere.2007.01.023

Kearn, J., Lilley, C., Urwin, P., O'Connor, V. and Holden-Dye, L., (2017). Progressive metabolic impairment underlies the novel nematicidal action of fluensulfone on the potato cyst nematode Globodera pallida. Pesticide Biochemistry and Physiology.

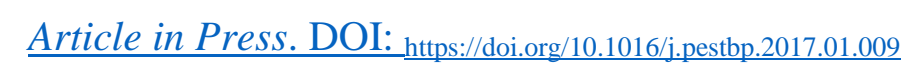

Morris, K.A., Langston, D.B., Dickson, D.W., Davis, R.F., Timper, P. \& Noe, J.P. (2015). Efficacy of Fluensulfone in a Tomato-Cucumber Double Cropping System. Journal of Nematology ${ }_{47}, 3_{10}-3_{15}$.

Noling, J.W. (2003). Movement and toxicity of nematicides in the plant root zone in Fact Sheet ENY-041 (formerly RF-NG002) 2003. DOI: http://edis.ifas.ufl.edu/ng002. (accessed 5 May 2011). 
1 Norshie, P.M., Grove, I.G. \& Back, M.A., (2016). Field evaluation of the nematicide 2 fluensulfone for control of the potato cyst nematode Globodera pallida. Pest 3 management science ${ }_{72}, 2_{001}-2_{007}$. DOI: $10.1002 /$ ps.4329.

4 Oka, Y. (2014). "Nematicidal activity of fluensulfone against some migratory nematodes under laboratory conditions." Pest Management Science $70,1_{850} 1_{858}$. DOI: 10.1002/ps.3730

Oka, Y., Shuker, S. \& Tkachi, N. (2009). Nematicidal efficacy of MCW-2, a new nematicide of the fluoroalkenyl group, against the root-knot nematode, Meloidogyne javanica. Pest Management Science ${ }_{65}, 1_{082}{ }_{1089}$. DOI: $10.1002 /$ ps.1796

9 Oka, Y., Shuker, S. \& Tkachi, N. (2012). Systemic nematicidal activity of fluensulfone

Opperman, C.H. \& Chang, S. (1990). Plant-parasitic nematode acetylcholinesterase inhibition by carbamate and organophosphate nematicides. Journal of Nematology 22 , $4_{81}-4_{88}$

Osborn, R.K., Edwards, S.G., Wilcox, A. \& Haydock, P.P.J. (2010). Potential enhancement of degradation of the nematicides aldicarb, oxamyl and fosthiazate in UK agricultural soils through repeated applications. Pest Management Science 66, 253-261. DOI:

Rich, J.R., Dunn, R.A. \& Noling, J.W., (2004). Nematicides: Past and present uses. In: Chen ZX, Chen SY and Dickson DW, (Eds) Nematology Advances and Perspectives Volume 

$1_{179}-1_{200}$.

Ryan, N.A., Deliopoulos, T., Jones, P. \& Haydock, P.P.J. (2003). Effects of a mixed-isolate mycorrhizal inoculum on the potato - Potato cyst nematode interaction. Annals of Applied Biology ${ }_{143}, 1_{11}-1_{19}$. DOI: 10.1111/j.1744-7348.2003.tb00275.x

Smelt, J.H. \& Leistra, M., (1992). Availability, movement and (accelerated) transformation of soil-applied nematicides. In: Gommers FJ and Maas PW Th (Eds) Proceedings Second International Nematology Congress. European Society of Nematologists. pp. $266-293$.

Whitehead, A.G. (1992). Emergence of juvenile potato cyst-nematodes Globodera rostochiensis and Globodera pallida and the control of G. pallida. Annals of Applied Biology ${ }_{120}, 4_{71}-4_{86}$. DOI: $10.1111 /$ j.1744-7348.1992.tb04907.x

Whitehead, A.G., Nichols, A.J.F. \& Senior, J.C. (1991). Control of potato pale cystnematode, Globodera pallida, with a granular nematicide and partially resistant potatoes. Annals of Applied Biology 118, 623-636. DOI: 10.1111/j.1744-7348.1991.tb05352.x

Whitehead, A.G., Nichols, A.J.F. \& Senior, J.C. (1994).The control of potato pale cystnematode (Globodera pallida) by chemical and cultural methods in different soils. TJ. Agricultural Science ${ }_{123}, 2_{07}-2_{18}$. DOI: https://doi.org/10.1017/S0021859600068477

Whitehead, A.G., Tite, D.J., Fraser, J.E. \& Nichols, A.J.F. (1984). Differential control of potato cyst nematodes, Globodera rostochiensis and G. pallida, by oxamyl and the yields of resistant and susceptible potatoes in treated and untreated soils. Annals of Applied Biology 105, 231-244. DOI: 10.1111/j.1744-7348.1984.tb03047.x 
Table 1. Time phase of the mobile-phase system for analyzing fluensulfone*.

$$
\text { Step Time (minutes) } \quad \text { Interval } \quad \text { Acetonitrile (\%) } \quad 0.1 \% \text { Orthophosphoric acid (\%) }
$$

\begin{tabular}{lcccc}
\hline 0 & $0-1$ & 1 & 30 & 70 \\
1 & $10-19$ & 9 & 45 & 55 \\
2 & $24-29$ & 5 & 95 & 5 \\
3 & $31-33$ & 2 & 30 & 70 \\
\hline *. Time phase
\end{tabular}

Table 2. Dissipation rates constant $\left(k\right.$, day $\left.^{-1}\right)$ and coefficient of determination $\left(r^{2}\right)$ obtained for nematicides fluensulfone and fosthiazate in potato beds treated with Nimitz 15 at $27 \mathrm{~kg} \mathrm{ha}^{-1}$ and Nemathorin 10G at $30 \mathrm{~kg} \mathrm{ha}^{-1}$ at Woodcote in 2010 and at Howle in 2011. Values are means \pm standard error.

\begin{tabular}{lcccc}
\hline Field Site & Nematicide & $\mathrm{k}$, day $^{-1}$ & $r^{2}$ & Significance \\
\hline Woodcote (2010) & Fluensulfone & $2.36 \pm 0.40$ & $95.45 \pm 0.20$ & $P<0.0001$ \\
Woodcote (2010) & Fosthiazate & $0.03 \pm 0.01$ & $94.87 \pm 0.18$ & $P<0.0001$ \\
Howle (2011) & Fluensulfone & $2.12 \pm 0.28$ & $96.45 \pm 0.13$ & $P<0.0001$ \\
Howle (2011) & Fosthiazate & $3.13 \pm 0.54$ & $97.15 \pm 0.20$ & $P<0.0001$ \\
\hline
\end{tabular}




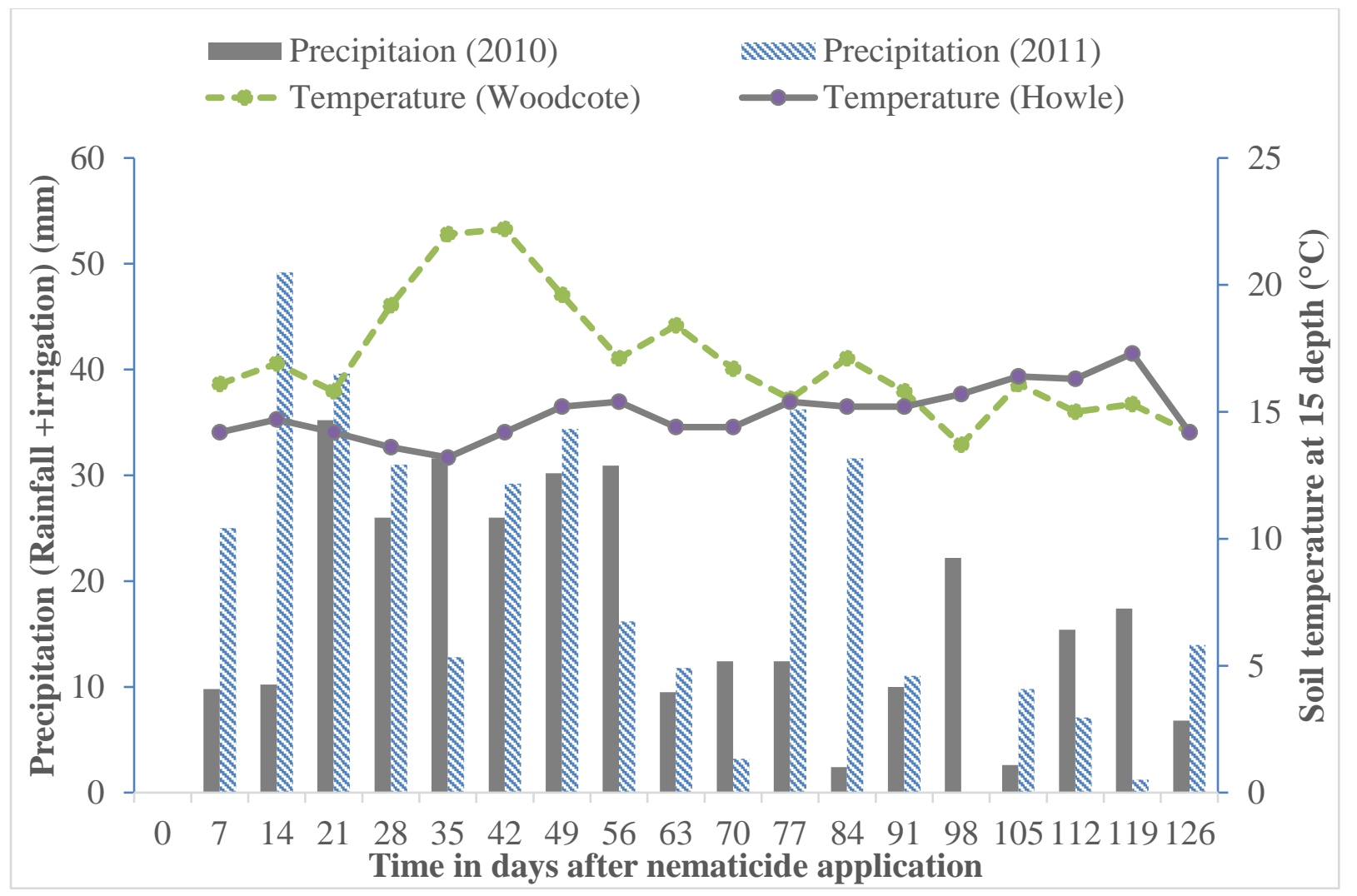

Figure 1. Mean soil temperature $\left({ }^{\circ} \mathrm{C}\right)$ at $15 \mathrm{~cm}$ depth of potato beds and total precipitation (rainfall + irrigation) as recorded at Harper Adams University over 126 days of in-field dissipation studies of nematicides fluensulfone and fosthiazate at Woodcote in 2010 and at Howle in 2011. 

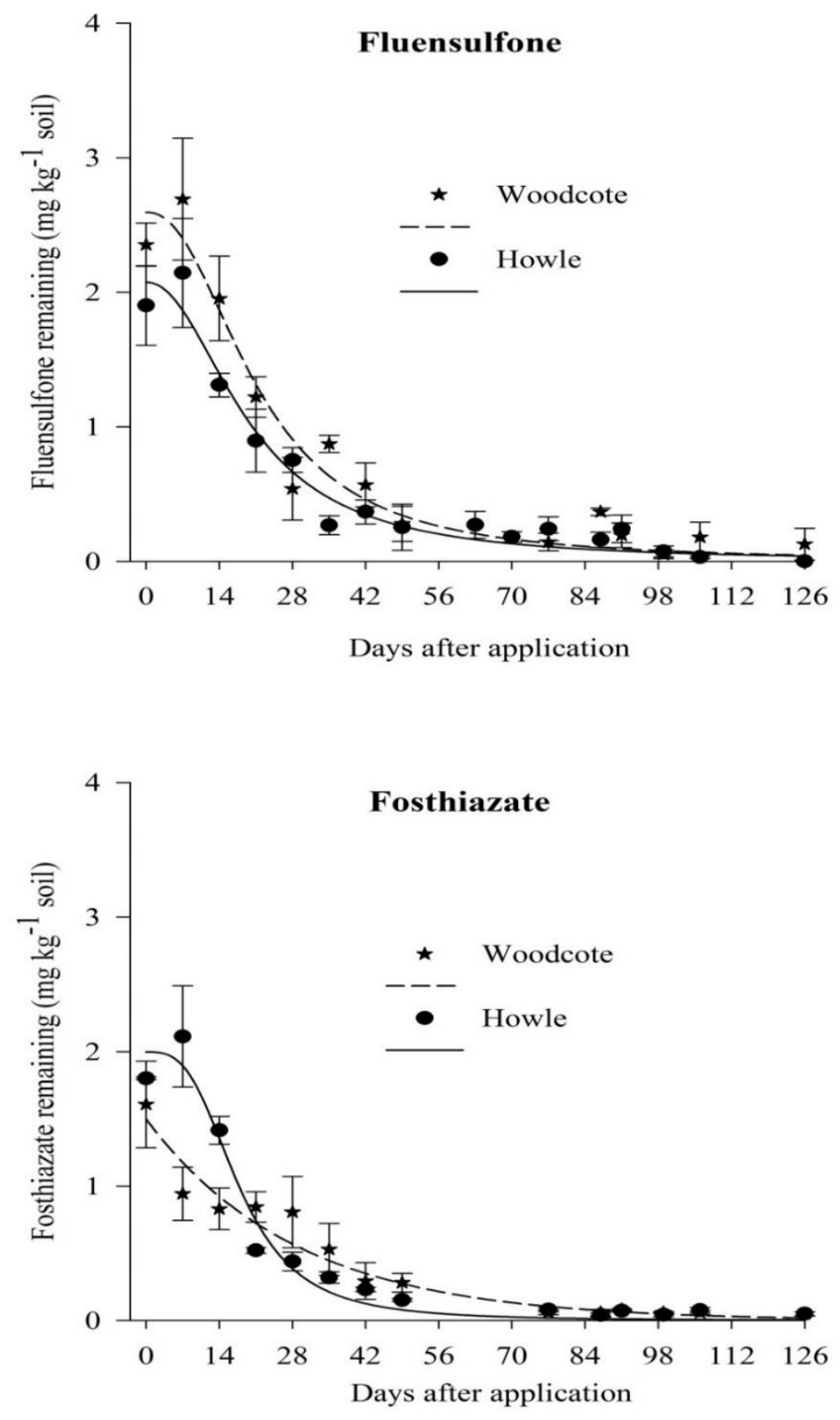

Fig. 2. Nematicides fluensulfone and fosthiazate quantified in the topmost $20 \mathrm{~cm}$ soil layer of potato beds following treatments with Nimitz $15 \mathrm{G}$ at $27 \mathrm{~kg} \mathrm{ha}^{-1}$ and Nemathorin $10 \mathrm{G}$ at $30 \mathrm{~kg} \mathrm{ha}^{-}$ ${ }^{1}$ at Woodcote in 2010 and at Howle in 2011. The loss of fluensulfone followed the equations $\mathrm{Y}=$ $4.04 /\left(1+^{(-(\mathrm{X}-10.38) /-16)}\right)$ at Woodcote and $\mathrm{Y}=2.64 /\left(1+^{(-(\mathrm{X}-15.66) /-11.7)}\right)$ at Howle. The loss of fosthiazate followed $\mathrm{Y}=1.47^{-0.03 \mathrm{X}}$ at Woodcote and $\mathrm{Y}=2.12 /\left(1+^{(-(\mathrm{X}-17.78) / 6.08)}\right)$ at Howle. 


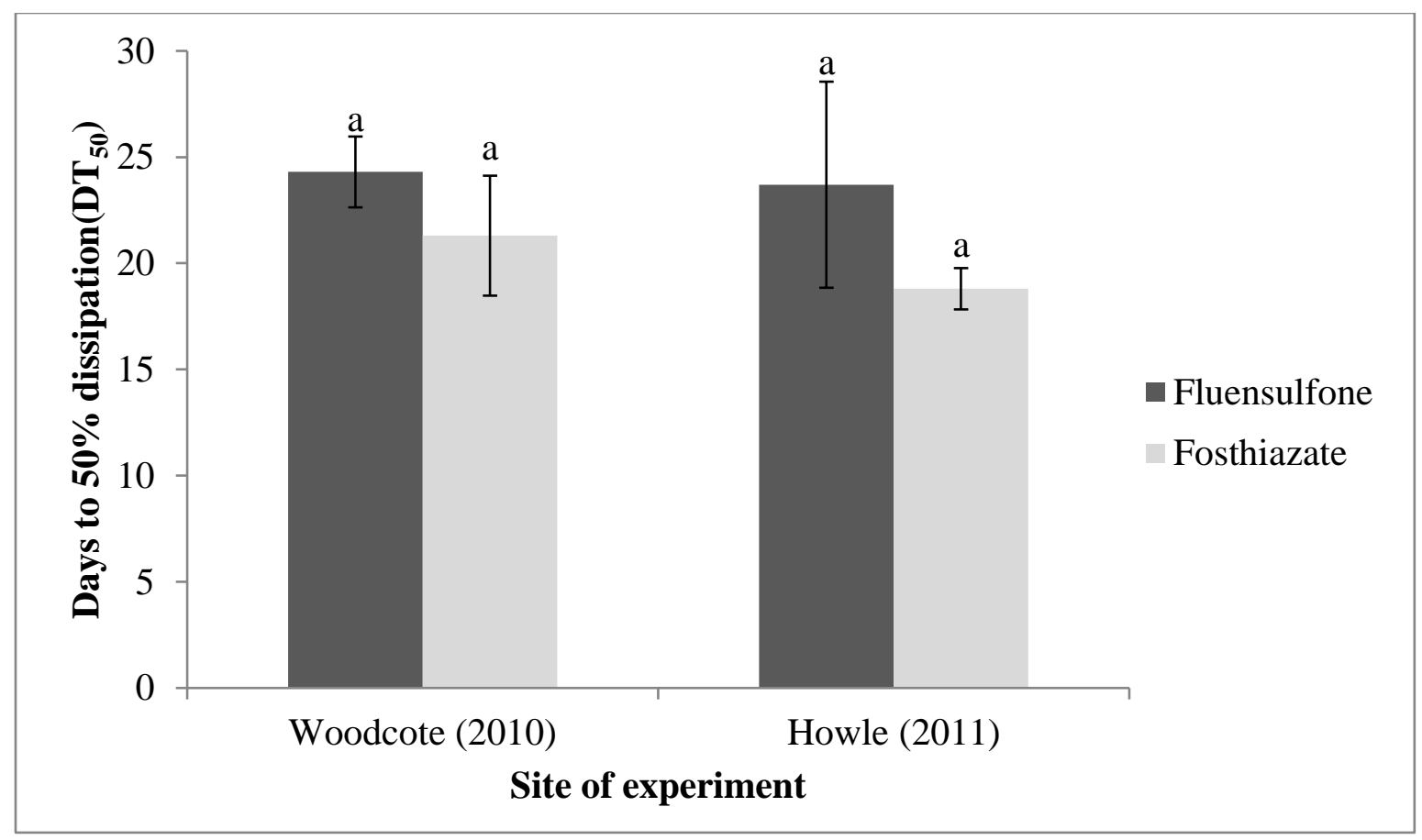

Figure 3. Comparisons of half-lives $\left(\mathrm{DT}_{50}\right)$ obtained for nematicides fluensulfone and fosthiazate at $20 \mathrm{~cm}$ depth of potato beds treated with Nimitz $15 \mathrm{G}$ at $27 \mathrm{~kg} \mathrm{ha}^{-1}$ and Nemathorin $10 \mathrm{G}$ at $30 \mathrm{~kg}$ $\mathrm{ha}^{-1}$ at Woodcote in 2010 and at Howle in 2011. Bars represent standard error values $(\mathrm{n}=5)$. 

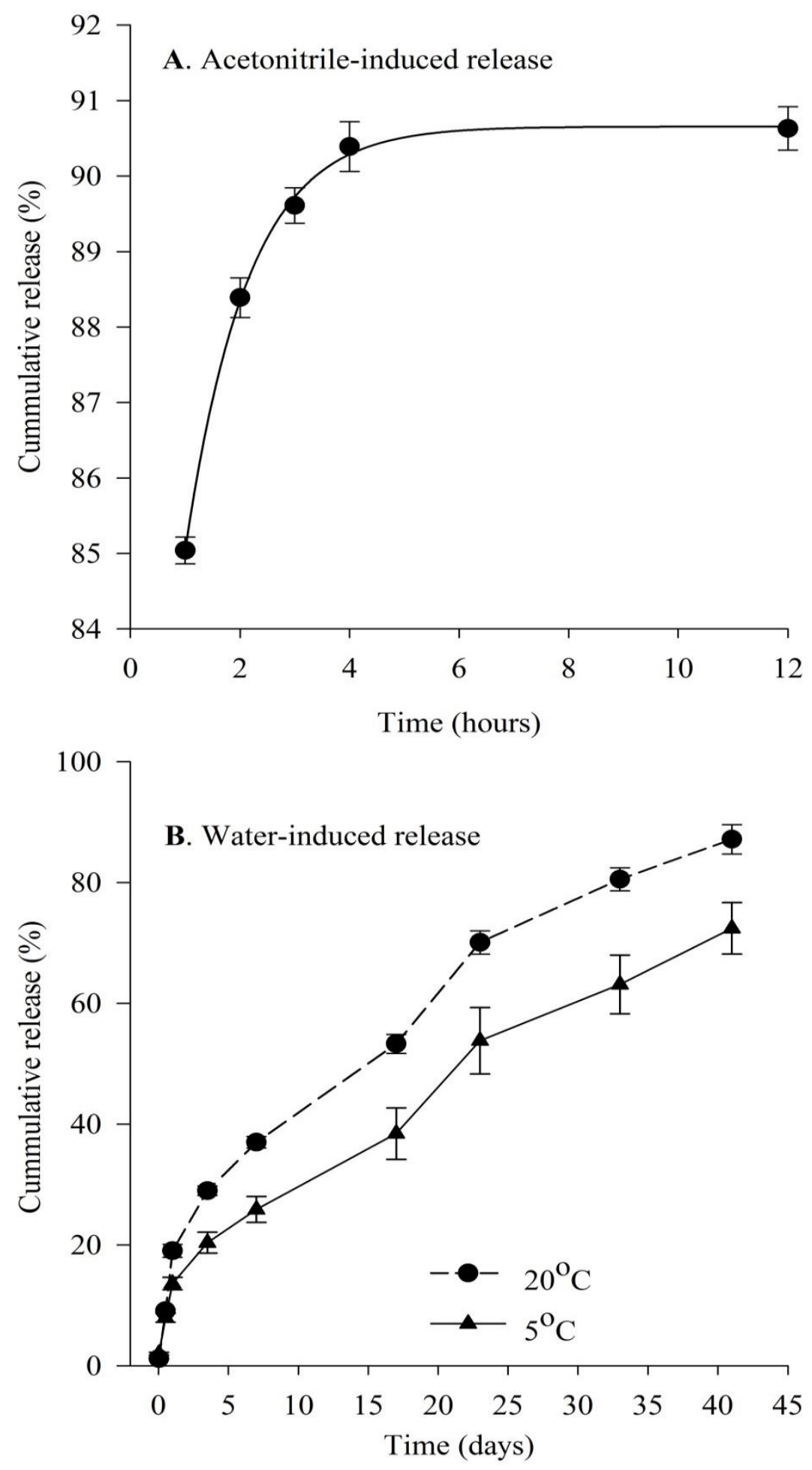

2 Figure 4. (A) Fluensulfone extracted from the granular formulation with acetonitrile over

$312 \mathrm{~h}$ and (B) water-induced release kinetics of fluensulfone from the granular formulation

4 over 41 days. Percentage cumulative release was plotted against duration of incubation. Bars 5 show the standard error of the mean $(n=3)$ 